\title{
Effect of patent ductus arteriosus stenting on subsequent bidirectional Glenn anastomosis: A word of caution
}

\author{
Ghassan Baslaim, MD, Jeddah, Saudi Arabia
}

$\mathrm{P}$ atent ductus arteriosus (PDA) stent implantation in patients with cyanoticcongenital heart disease and ductdependent pulmonary blood flow is technically feasible and provides an effective alternative to surgical systemicto-pulmonary artery shunts. ${ }^{1}$

In this report 3 cases of constructed bidirectional Glenn (BDG) shunt preceded by PDA stent implantation have resulted in an unexpected complicated course. To the best of my knowledge, no reports have appeared describing such a postoperative complication.

\section{Clinical Summary}

Three patients underwent BDG shunt procedures after previous PDA stent implantation for their duct-dependant pulmonary blood flow congenital heart disease (Table 1). All 3 patients had complete preoperative cardiac evaluation, and none of them were subjected to previous cardiovascular surgeries.

All BDG shunt procedures were performed through a median sternotomy. The superior vena cava was anastomosed in an end-to-side fashion to the right pulmonary artery, and the PDA was ligated. Therefore no additional source of pulmonary blood flow was maintained. Concomitant surgical procedures performed were atrial septectomy $(\mathrm{n}=2)$ and tricuspid valve closure $(n=1)$.

Postoperatively, because of critical arterial oxygen saturation (range, 35\%-66\%) and high central venous pressure (range, 24-28 $\mathrm{mmHg}$ ), all 3 patients were kept intubated and sedated. All 3 patients experienced significant edema of the upper body and borderline urine output. These patients experienced a progressive increase in the requirement of pulmonary vasodilators and inotropes in addition to the use of nitric oxide. Lung biopsy was not performed on any of the 3 patients, and an autopsy study was not done on any of the patients who died.

From the Division of Cardiothoracic Surgery, Department of Cardiovascular Diseases, King Faisal Specialist Hospital and Research Center, Jeddah, Saudi Arabia.

Received for publication Dec 7, 2005; accepted for publication Dec 27, 2005.

Address for reprints: Ghassan Baslaim, MD, MBC-J 16, PO Box 40047, Jeddah 21499, Saudi Arabia (E-mail: gbaslaim@ @otmail.com).

J Thorac Cardiovasc Surg 2006;131:e3-4

$0022-5223 / \$ 32.00$

Copyright $\odot 2006$ by The American Association for Thoracic Surgery

doi:10.1016/j.jtcvs.2005.12.024

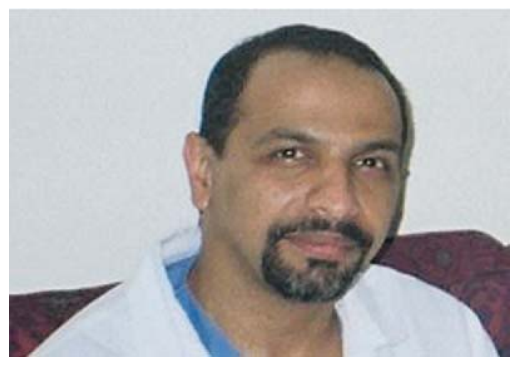

Dr G. Baslaim

\section{Results}

Patient 1. This patient had a mean gradient of $4 \mathrm{~mm} \mathrm{Hg}$ across the anastomosis of the BDG shunt, as determined by means of echocardiography. Successful interventions were done on postoperative days (PODs) 3 and POD 5. Finally, on POD 8, the patient underwent construction of a $6 \mathrm{~mm}$ Blalock-Taussig (BT) shunt and takedown of the BDG shunt, after which she was extubated.

Patient 2. This patient underwent attempted cardiac catheterization on POD 2, but unfortunately, during percutaneous vascular access trials, the left internal carotid artery was injured, and the patient was subjected to an emergency operative procedure. She remained hypoxic and in critical condition after the emergency operation and died on the following day.

Patient 3. This patient had a mean gradient of 3 to $4 \mathrm{~mm} \mathrm{Hg}$ across the anastomosis of the BDG shunt. He remained hypoxic and in critical condition, and on POD 10, a 3-mm BT shunt was constructed as an additional source of pulmonary blood flow, and the BDG shunt was revised. The patient's condition continued to deteriorate, and he died 2 days later.

\section{Discussion}

Modified forms of the BT shunt are preferred over central shunts for the simplicity of operative discontinuation and less incidence of pulmonary hypertension. ${ }^{2}$ However, PDA stent implantation has been advocated as a safe and effective palliative technology instead of surgical systemic-to-pulmonary artery shunt, allowing adequate pulmonary blood flow and growth of the pulmonary arteries. $^{1}$

Increased pulmonary artery pressures can complicate the outcome after a BDG shunt procedure. Nonetheless, patients coming for a BDG shunt procedure with a BT shunt previously placed might have an abnormal pulmonary vascular bed because of pulmonary atresia and therefore might be less ideal candidates. ${ }^{3,4}$ Furthermore, the requirement of additional pulmonary blood flow through a BT shunt at the time of placement of the BDG shunt might be a surrogate marker for a borderline candidate. $^{4}$

Each of the 3 patients described herein required modification of the postoperative management to maintain pulmonary blood flow. Such an occurrence in the early postoperative period reflects a borderline candidacy for BDG shunt, and the underlying mechanism was thought to be related to pulmonary hypertension precipitated by the central shunt-like effect of the previously stented PDA. Although it is a small series, certain issues can be considered. First, in patients with a previously stented PDA, preoperative borderline hemodynamic parameters 
TABLE 1. Summary of clinical data

\begin{tabular}{|c|c|c|c|c|}
\hline & & Patient 1 & Patient 2 & Patient 3 \\
\hline \multirow[t]{6}{*}{ Before BDG } & Age at BDG shunt/sex & $5 \mathrm{mo} / \mathrm{F}$ & $4 \mathrm{mo} / \mathrm{F}$ & $4 \mathrm{mo} / \mathrm{M}$ \\
\hline & Diagnosis & TA/PA & PA/IVS & PA/IVS \\
\hline & Age at PDA stenting & 3 wk & 4 wk & 4 wk \\
\hline & Size of PDA stent & $6.0 \mathrm{~mm}$ & $4.5 \mathrm{~mm}$ & $4.5 \mathrm{~mm}$ \\
\hline & PDA stent reintervention & $\begin{array}{l}2 \text { wk later, additional } \\
6.0-\mathrm{mm} \text { stent }\end{array}$ & None & $\begin{array}{l}13 \text { wk later, stent } \\
\text { balloon dilatation }\end{array}$ \\
\hline & $\begin{array}{l}\text { Pre-BDG hemodynamics: } \\
\text { MPAP/PVR }\end{array}$ & $23 \mathrm{~mm} \mathrm{Hg} / 4.0 \mathrm{WU}$ & $\begin{array}{l}25 \mathrm{~mm} \mathrm{Hg} / 5.5 \mathrm{WU}, \mathrm{PVR} \\
\text { dropped to } 1.5 \mathrm{WU} \text { with } \\
100 \% \text { oxygenation }\end{array}$ & 15 mm Hg/4.5 WU \\
\hline \multirow[t]{4}{*}{ After BDG } & Cardiac catheterization & $\begin{array}{l}\text { MPAP }=15 \mathrm{~mm} \mathrm{Hg}, \\
\text { BDG mean gradient }= \\
4 \mathrm{~mm} \mathrm{Hg}\end{array}$ & $\begin{array}{l}\text { Attempted but complicated } \\
\text { with LICA injury }\end{array}$ & $\begin{array}{l}\text { MPAP }=20 \mathrm{~mm} \mathrm{Hg}, \\
\text { BDG mean gradient }= \\
3-4 \mathrm{~mm} \mathrm{Hg}\end{array}$ \\
\hline & Intervention & $\begin{array}{l}\text { Dilatation of BDG } \\
\text { anastomosis \& coiling } \\
\text { VV collateral } x 1\end{array}$ & None & None \\
\hline & Reoperation & $\begin{array}{l}\text { BT shunt }(6 \mathrm{~mm}) \text { and } \\
\text { takedown of BDG }\end{array}$ & $\begin{array}{l}\text { Emergency LICA repair, BT } \\
\text { shunt ( } 5 \mathrm{~mm}) \text {, and } \\
\text { takedown of BDG }\end{array}$ & $\begin{array}{l}\text { BT shunt }(3 \mathrm{~mm}) \text { and } \\
\text { revision of } B D G\end{array}$ \\
\hline & Outcome & $\begin{array}{l}\text { Alive and discharged } \\
\text { home }\end{array}$ & Died on POD (BDG) 3 & Died on POD (BDG) 13 \\
\hline
\end{tabular}

BDG, Bidirectional Glenn, TA, tricuspid atresia; $P A$, pulmonary atresia; IVS, intact ventricular septum; $P D A$, patent ductus arteriosus; $M P A P$, mean pulmonary artery pressure; $P V R$, pulmonary vascular resistance; $W U$, wood's unit; $L I C A$, left internal carotid artery; $V V$, venovenous; $P O D$, postoperative day.

for a BDG shunt should be taken into serious consideration. Second, low thresholds for an earlier BDG shunt construction from the time of PDA stenting must be considered. Third, a PDA stent larger than $4.0 \mathrm{~mm}$ should be discouraged for singleventricle patients. Fourth, takedown of a BDG shunt and construction of a BT shunt is a safe measure to implement in borderline cases, although in the literature there is controversy as to whether an additional source of pulmonary blood flow after placement of a BDG shunt has any beneficial effect. Finally, in view of the fact that placement of a BDG shunt is an important staging procedure in the management of patients with complex single-ventricle physiology; further long-term studies are certainly needed to determine the size, duration, and hemodynamic effect of PDA stenting in palliating single-ventricle patients before placement of a BDG shunt.

\section{References}

1. Behnke-Michel I, Akintuerk H, Thul J, Bauer J, Hagel K-J, Schranz D. Stent implantation in the ductus arteriosus for pulmonary blood supply in congenital heart disease. Catheter Cardiovasc Interv. 2004;61:242-52.

2. Zellner JL, Sade RM. Palliative procedures in cyanotic congenital heart disease. In: Baue AE, Geha AS, Laks H, Hammond G, Naunheim K, editors. Glenn's thoracic and cardiovascular surgery. 6th ed. Stamford, Conn: Appleton \& Lange; 1996. p. 1073-83.

3. McElhinney DB, Marianeschi SM, Reddy VM. Additional pulmonary blood flow with the bidirectional Glenn anastomosis: does it make a difference? Ann Thorac Surg. 1998;66:668-72.

4. Berdat PA, Belli E, Lacour-Gayet F, Planché C, Serraf A. Additional pulmonary blood flow has no adverse effect on outcome after bidirectional cavopulmonary anastomosis. Ann Thorac Surg. 2005;79: 29-37. 